\title{
Husserl: significação e fenômeno
}

\author{
Carlos Alberto Ribeiro de Moura \\ Universidade de São Paulo
}

\begin{abstract}
resumo 0 objetivo deste artigo é discutir o modo como Husserl desenha a originalidade da subjetividade transcendental, frente à sua homônima psicológica. Se é certo que a noção de "imanência autêntica" pode apontar para as diferentes fronteiras entre o transcendental e o psicológico, resta que por si só ela não permite decidir nada quanto ao "modo de ser" transcendental, em sua diferença face ao "mundano". Sendo assim, procura-se reconstituir alguns dos momentos centrais do esforço husserliano para construir um conceito de "subjetivo" e de "subjetividade" que não se confunda mais com o "psíquico" da psicologia tradicional.
\end{abstract}

palavras-chave subjetividade - psique - fenômeno - noema - transcendental

Sabe-se que a originalidade da noção husserliana de "subjetividade transcendental" pareceu muito enigmática a discípulos e intérpretes. "A epoché fenomenológica - escreve Husserl - libera uma esfera de ser nova e infinita, como esfera de uma experiência nova, a experiência transcendental" (HUSSERL, 1973a, p. 66). Mas, de imediato, não parece ser tão claro o que haveria de inédito nesta subjetividade chamada de transcendental, face à sua homônima mundana. Os textos repetem à exaustão que a responsável pela novidade é a redução, única operação capaz de desvelar o "território fenomenológico" (HUSSERL, 1950, p. 145). Mas a pretensa novidade da subjetividade transcendental face à psicológica

Recebido em 15 de dezembro de 2005. Aceito em 31 de janeiro de 2006.

doispontos, Curitiba, São Carlos, vol. 3, n. 1, p.37-61, abril, 2006 
parece indecifrável. A redução, compreendida como "suspensão da tese geral da atitude natural", quer dizer, como inibição da validade e da "crença no mundo", não parece, por si só, instruir-nos sobre o caráter inédito da subjetividade que ela promete desvelar. Se essa penumbra, por si só, já confere ao transcendental uma perigosa indistinção face ao psicológico, é essa promiscuidade entre ambos que parece ser mais sublinhada do que amortecida pela tese que afirma a existência simultânea não só de uma diferença, mas também de uma identidade entre o transcendental e o mundano, uma doutrina que parece antes obscurecer a relação entre eles, além de tornar tenazmente impalpável a pretensa novidade dessa região do transcendental, face ao seu eco mundano.

Assim, por um lado Husserl afirma a existência de uma diferença necessária e de princípio entre a subjetividade transcendental e a psicológica. Afinal, seria um contra-senso elementar formular questões transcendentais sobre a possibilidade do conhecimento objetivo a partir de uma subjetividade que, sendo "mundana", faz parte, ela mesma, do problema a ser resolvido. Para não incorrer em um círculo vicioso elementar, a subjetividade "pura” alcançada pela redução não poderá ser aquela do "homem" - o "psicologismo", na sua forma a mais radical, sendo justamente o desvio de conduta que consiste em formular questões transcendentais a partir de uma subjetividade que é, ela mesma, "parte" do mundo (HUSSERL, 1968a, p. 249). Assim, a redução fenomenológica introduz "uma espécie de cisão do eu", em que o "espectador transcendental" encontra a si mesmo como "homem", mas apenas enquanto correlato de sua vida transcendental (HUSSERL, 1973a, p. 16). Desde então, se a psicologia pura já exerce a epoché da validade em relação ao mundo, a fenomenologia exigirá uma redução universal, uma redução que inclua a própria alma, sempre poupada pelo psicólogo (HUSSERL, 1968a, p. 249). Por isso a vida transcendental não será vida "do homem" mas sim "do ego", onde o homem e o mundo têm seu "ser constituído" (HUSSERL, 1973c, p. 539). Se essa subjetividade transcendental tem como seus objetos as coisas espaço-temporais, ela mesma não está no espaço, não está no tempo, não está no mundo. A exposição (Darstellung) do mundo - dirá Husserl - não está, ela mesma, no mundo, a "vida subjetiva" que percebe, se recorda ou simplesmente visa no vazio não está, ela mesma, no mundo (HUSSERL, 1973c, p. 644-645). Sendo assim, nenhu- 
ma surpresa em se dizer que o eu obtido pela redução é chamado de “eu” apenas "por equívoco" (HUSSERL, 1962, p. 188). É em função dessa diferença de princípio que se falará agora em um "paralelismo" entre a subjetividade transcendental e a psicológica.

Mas essas subjetividades "diferentes" também são idênticas entre si, e por isso Husserl sublinhará que a metáfora das paralelas nunca deve nos extraviar, nunca deve sugerir a ninguém a idéia de uma duplicação da subjetividade. Afinal, não se deve duvidar de que o Eu absoluto de Fichte, que se põe a si mesmo, não seja o próprio eu de Fichte (HUSSERL, 1962, p. 205). E se é certo que meu eu transcendental é evidentemente diferente do meu eu natural, não é menos certo - assegura Husserl - que ele "não o é como um segundo eu, como algo separado dele no sentido natural da palavra, assim como, ao contrário, ele não é de maneira alguma algo de unido ou entrelaçado a ele no sentido natural" (HUSSERL, 1968a, p. 294). Desde então, se é verdade que o ego não é o homem, não é uma parte do mundo, é verdade também que o eu natural é um eu transcendental que se desconhece como tal e que "eu sou o mesmo como ego e como pessoa humana”(HUSSERL, 1973c, p. 540) E se é assim, dirá Husserl, “... a psicologia e a filosofia transcendental são aparentadas uma à outra de modo inseparável e peculiar, no modo que para nós não é mais enigmático, da identidade e da diferença entre o eu psicológico (logo, humano, mundanizado no mundo espaço-temporal) e a vida egóica e o operar do eu transcendental" (HUSSERL, 1962, p. 209).

Uma identidade e diferença que não são mais enigmáticas? Mas qual a natureza da diferença entre o transcendental e o psicológico se eles são idênticos e não duplos? E como pode haver identidade sem duplicação se a distância entre ambos é aquela que existe entre o sujeito e o objeto, o constituinte e o constituído? Da mesma maneira, como não falar em "separação" entre uma subjetividade que é parte do mundo e um ego transcendental que, por princípio, sempre estará "fora" do mundo? Agora, é o próprio sentido e estatuto do "transcendental" husserliano que inevitavelmente se obscurece. E se é assim, Heidegger tinha toda a razão em suas observações ao artigo que Husserl escrevia para a Enciclopédia Britânica, ao reclamar ali uma explicitação sobre qual seria, no final das contas, o "modo de ser" dessa subjetividade chamada de "transcendental", diante de sua sósia mundana. O que significa, pergunta Heidegger,"o ego abso- 
luto na sua diferença em face ao puro anímico? Qual é o modo de ser (Seinsart) desse ego absoluto - em que sentido ele é o mesmo que o eu sempre fáctico; em que sentido ele não é o mesmo?” E, concordando com Husserl quanto à "evidência" de que a "constituição transcendental" do mundo não poderia ser elucidada pelo retorno a um "ente" que tivesse o mesmo "modo de ser" deste mundo, Heidegger se apressava em sugerir que aquele território inédito poderia muito bem ser o "Dasein humano", o "homem concreto"1. Uma "sugestão" que para Husserl, como se sabe, significava pura e simplesmente reatar com o "antropologismo", o "psicologismo", desconhecendo o sentido mesmo da "redução" e o caráter inédito do território que ela deveria desvelar (HUSSERL, 1989, p. 164).

É verdade que sempre se pode circunscrever a diferença entre a subjetividade psicológica e a transcendental através da distância existente entre a imanência "real" (reell) e a imanência "autêntica" ou "transcendental". Afinal, é apenas quando nós nos situamos na atitude natural que, espontaneamente, a imanência se identifica à imanência real, a um "interior" do sujeito psicológico que se opõe a um "exterior" mundano. Pois quando eu me apreendo como "homem natural" - dirá Husserl - "de antemão eu já apercebi o mundo espacial, já apreendi a mim mesmo no espaço, no qual eu já tenho um exterior a mim" (HUSSERL, 1973a, p. 116). A natürliche Einstellung é o código interpretativo subjacente à doutrina clássica ou cartesiana da representação visto que, sob sua direção, a pergunta transcendental pela possibilidade do conhecimento vai necessariamente se travestir na questão "psicológica" de se saber como o homem que vive no mundo pode obter e legitimar o conhecimento de um mundo exterior à alma (HUSSERL, 1968a, p. 265). Se em regime de redução todo objetivo se transforma em subjetivo, isso não significa, de forma alguma, que o novo "interesse" pelo subjetivo se traduza em um interesse pela "representação do mundo" (HUSSERL, 1962, p. 182). Ao contrário, antes de mover-se no círculo da pura "representação do mundo", a atitude transcendental será, para Husserl, exatamente o fim da cisão entre mundo e representação (HUSSERL, 1959, p. 480). É o "entendimento humano natural" que opõe uma interioridade psicológica a um exterior, assim como foi sua miopia - dirá Husserl - que fez com que, "durante séculos", ninguém, praticamente, "se tenha perguntado se, em relação a essa esfera 
de ser egológica, um 'exterior' em geral poderia ter um sentido" (HUSSERL, 1962, p. 83)2 ${ }^{2}$. Bem compreendida, a subjetividade transcendental não tem nada de exterior a si, visto que ela "abarca então a totalidade do subjetivo, no qual se inclui, finalmente, o próprio mundo enquanto subjetivamente constituído" (HUSSERL, 1973c, p. 288). E como seria diferente se, em regime de redução, o objeto da consciência não pode ser nada além da unidade sintética de seus múltiplos modos subjetivos de doação? (HUSSERL, 1968a, p. 153) Por isso a verdadeira questão "transcendental" sobre a possibilidade do conhecimento, longe de se traduzir em uma meditação mundana sobre a relação entre uma interioridade psicológica e um exterior "místico", será a de saber como uma multiplicidade de fenômenos subjetivos pode ser a apresentação, para a consciência, de um objeto idêntico, e que estruturas de evidência estão presentes nessa constituição.

Mas é certo também que essa distância entre o psicológico e o transcendental, opondo-os através de suas distintas fronteiras, por si só ainda não responde em nada ao reclamo de Heidegger por uma explicitação do "modo de ser" da subjetividade transcendental, diante de sua gêmea psicológica. Afinal, o que garante que este "transcendental" não seja o velho "psíquico", apenas com sua fronteira expandida até abarcar a totalidade do "mundo"? Assim como essa diferença de fronteiras nada esclarece sobre a identidade entre o eu psicológico e o eu transcendental, o constituído e o constituinte. Donde as soluções extremas apresentadas seja pela posteridade de Husserl, seja por seus comentadores. Para que "o Eu transcendental e o eu empírico possam ser 1) irredutíveis 2) idênticos - dirá Merleau-Ponty - é preciso que o Eu transcendental seja nada (que 'não é') e o eu empírico ser' (MERLEAU-PONTY, 2002, n.92a). Simetricamente, De Boer se pergunta como o eu puro constituinte e o eu real constituído poderiam ser um e o mesmo se suas propriedades se excluem reciprocamente e, por isso, não podem pertencer à unidade de um objeto. Assim, concluirá De Boer, apenas se a consciência psicológica for vista como uma ficção, uma espécie de ilusão transcendental, é que se pode entender como Husserl pôde sustentar "a identidade da consciência psicológica e da consciência transcendental” (DE BOER, 1978, p. 465)³. Essas soluções simétricas e inversas resolvem o problema eliminando um dos termos em disputa, quer dizer, diluindo o problema. E se é assim, 
tentemos atalhar a questão perguntando, pelo menos, se Husserl fornece elementos para se discernir qual seria o "modo de ser" da subjetividade transcendental, em sua diferença frente à região do "psicológico".

\section{II}

Em 1901, nas Investigações lógicas, Husserl circunscrevia a região da subjetividade fenomenológica ou "pura" tomando como ponto de partida os conceitos da psicologia descritiva, apoiando-se na máxima brentaniana segundo a qual todos os fenômenos são ou físicos ou psíquicos (HUSSERL, 1968b, p. 345) ${ }^{4}$. Neste momento, Husserl considera essa classificação de Brentano como a "mais notável" e filosoficamente a "mais importante" (HUSSERL, 1968b, p. 364). E como a oposição brentaniana não é senão um Ersatz do dualismo cartesiano, não é nada surpreendente que a subjetividade fenomenológica fizesse sua estréia na cena filosófica alemã sucumbindo aos mesmos prejuízos que, anos depois, Husserl censurará em Descartes. Segundo a regra da psicologia descritiva, se a "consciência" não remete a nada de físico, então ela só pode ser reportada aos "fenômenos psíquicos". Ali nas Investigações, Husserl parte dessa consciência psicologicamente decifrada para empreender a "purificação" que levará à subjetividade fenomenológica. Mas sabe-se que essa "purificação" - muito distinta daquela que será, posteriormente, a purificação "transcendental" - se resumirá, na verdade, a um duplo movimento: a abstração do corpo e a consideração da essência dos vividos, e não destes vividos como fatos individuais. A consciência fenomenológica - assegura Husserl - é atingida quando, analisando o eu empírico, nós “excluímos o corpo do eu, corpo que, como coisa fisica, aparece como qualquer outra, e consideramos o eu espiritual empiricamente ligado a ele, e que se manifesta como pertencente a ele" (HUSSERL, 1968b, p. 361). E se no plano da psicologia esse eu espiritual ou essa consciência podem ser definidos como a unidade real (reell) dos vividos de um eu, onde esses vividos são acontecimentos reais (realen) que, alterando-se e entrelaçando-se entre si, "formam a unidade real (reell) da consciência do indivíduo psíquico correspondente", nós podemos passar dessa caracterização psicológica da consciência à sua delimitação propriamente fenomenoló- 
gica quando, eliminando "toda referência a uma existência empírico-real (reales) (aos homens ou aos animais da natureza)", nós apreendemos esses vividos como essências e não como fatos individuais. Agora, assegura Husserl, "o vivido em sentido psicológico-descritivo se converte então em vivido no sentido da fenomenologia pura" (HUSSERL, 1968b, p. 348). Desligada de todo e qualquer indivíduo, essa consciência eideticamente purificada só poderá ser uma consciência em geral, uma subjetividade anônima ou "de ninguém", e que por esse viés se distancia da consciência sempre individualizada de que trata a psicologia empírica.

Mas se a subjetividade fenomenológica é obtida pela mera abstração do corpo, a passagem do fato à essência só nos oferecerá o eidos do psíquico, essa camada do mundo sobre a qual se debruça a psicologia. A subjetividade sobre a qual a fenomenologia pré-transcendental trabalha é apenas um resíduo do mundo, assim como a alma cartesiana era o resíduo da abstração do corpo. A consciência e o corpo formam uma unidade psicofísica, ambos são camadas pertencentes ao mundo, separados apenas metodicamente. Essa idéia de uma justaposição entre subjetividade e corpo, separados metodicamente por um processo de abstração, será característica do "modo de pensamento" que, posteriormente, Husserl atribuirá à atitude natural: nessa atitude a psique e a natureza fisica, na qual está incluído o corpo, separam-se como dois componentes de um mesmo mundo (HUSSERL, 1962, p. 216). E se é assim, essa subjetividade ainda é uma região interior ao mundo, e não a verdadeira subjetividade transcendental, "que não é mais uma pura região abstrata no interior do mundo”(HUSSERL, 1950, p. 394). Por isso, como Husserl reconhecerá alguns anos depois, a sua primeira fenomenologia era na verdade apenas uma "psicologia racional", e as Investigações não podiam libertar-se do psicologismo "sob sua forma mais essencial e mais universal" (HUSSERL, 1975, p. 405). Ali, a justa crítica ao psicologismo lógico ainda não se desdobrava em uma crítica ao "psicologismo transcendental". A "subjetividade fenomenológica" era apenas a essência de uma das regiões da "realidade".

Mas como superar o "psicologismo transcendental"? Nos seus cursos sobre a lógica e a teoria do conhecimento dos anos 1906-1907, Husserl ainda não alterava a sua doutrina da subjetividade, a fenomenologia sendo novamente apresentada como a disciplina que se afasta da psicologia por 
não reportar-se a uma subjetividade individual, mas a uma subjetividade em geral (HUSSERL, 1984, p. 168). Mas pelo menos ali ele já formulava com precisão a dificuldade da empreitada, assim como indicava o único caminho para se superar o psicologismo sob sua forma a "mais essencial". Por um lado - dirá Husserl -, se a fenomenologia é uma investigação sobre a possibilidade do conhecimento, se sua tópica básica é saber como a subjetividade pode ter acesso à transcendência, então aparentemente ela só pode ser uma psicologia,já que a subjetividade entra na própria formulação de seu problema, e conceitos noéticos como "perceber" ou "julgar" referem-se a acontecimentos psíquicos. Nessas condições, como uma investigação sobre a subjetividade não seria uma psicologia? Mas, por outro lado, como identificar a teoria do conhecimento à psicologia, se a questão crítica sobre a possibilidade do conhecimento, tal como a filosofia a formula, também diz respeito à própria psicologia, enquanto uma ciência da natureza entre as outras, questionável portanto quanto à possibilidade e o sentido de sua validade objetiva? Segundo essa outra ótica, recorrer à psicologia é perder de vista o próprio sentido dos problemas de uma autêntica teoria do conhecimento, é ingressar em um círculo vicioso elementar. Donde a formulação que Husserl dará do "dilema" da fenomenologia: por um lado, identificar a teoria do conhecimento a uma psicologia é um gesto que contradiz o próprio sentido da teoria do conhecimento; mas, por outro lado, como não identificar teoria do conhecimento e psicologia se, sob o nome "conhecimento", o que temos, na verdade, são atividades psíquicas? Nessas circunstâncias, não é surpreendente que Husserl apresente a questão das relações entre psicologia e teoria do conhecimento como sendo "o mais importante dos problemas" situados na porta de entrada da filosofia (HUSSERL, 1984, p. 174).

Como resolver o problema? A única saída estará em descobrir um conceito de "subjetivo", de "subjetividade" e de "conhecimento" que não tenham mais nada a ver com a região mundana do "psíquico". Mas como chegar a isso? A primeira condição, ainda negativa, para pelo menos se começar a vislumbrar uma subjetividade não psíquica, será renunciar ao pressuposto que comandava a delimitação da região da "consciência" ali nas Investigações lógicas. Esse pressuposto era o axioma brentaniano segundo o qual todos os fenômenos são ou físicos ou psíquicos. Se essa "evidência" já tinha condenado a Filosofia da aritmética ao contra-senso do psico- 
logismo lógico, era ela também que destinava a fenomenologia das Investigações lógicas a enraizar-se no "psicologismo transcendental". As Investigações recusavam a universalidade da alternativa brentaniana no momento de fundamentar a lógica pura, mas preservavam sua ação soberana quando se tratava de circunscrever a região da consciência: se esta não designa nada de físico, então ela só pode referir-se à realidade "psíquica". Se, em 1901, a divisão brentaniana de todos os fenômenos em físicos e psíquicos era considerada por Husserl como a "mais notável" e filosoficamente a "mais importante", em 1906 ele já protestará contra a idéia, vista agora como "pseudo-evidente", oriunda do "pensamento natural", de que todo e qualquer dado é ou físico ou psíquico. Rompendo com esse pressuposto, garante Husserl, a redução fenomenológica pode mostrar como a palavra consciência "perde todo sentido psicológico, e finalmente somos reconduzidos a um absoluto que não é nem ser físico nem ser psíquico, no sentido da ciência da natureza" (HUSSERL, 1984, p. 242). O psicologismo é a identificação sumária do subjetivo ao psíquico, a confusão apressada da consciência com a alma. Isso pode soar paradoxal, reconhecerá Husserl, mas é "pensável” uma consciência sem alma, isto é, um fluxo de vividos onde não se constitui uma alma, onde os vividos no sentido psicológico não têm apoio nem validade (HUSSERL, 1950, p. 133). Desde então, o erro fundamental do psicologismo é a realização (Realisierung) da consciência transcendental, e o que mais importa - dirá Husserl - é reconhecer, contra ele, que "a consciência não é nenhum vivido psíquico, nenhum entrelaçamento de vividos psíquicos, nenhuma coisa, nenhum anexo (estado, atividade) em um objeto natural" 5 . É esse motivo antipsicologista que levará Husserl a apresentar os vividos analisados pela fenomenologia como sendo "irrealidades" (Irrealitäten) - e isso, não em virtude da redução eidética, mas sim por obra e graça da "purificação" transcendental (HUSSERL, 1950, p. 6/7). Frente à realidade, assegura ele, "o subjetivo é uma irrealidade. Realidade e irrealidade se co-pertencem essencialmente na forma realidade e subjetividade, aquilo que reciprocamente se exclui e, por outro lado, essencialmente se exige" (HUSSERL, 1952, p. 64)6. Mas, se é assim, o estatuto e o "modo de ser" do transcendental husserliano parecem depender do sentido e do alcance dessa caracterização geral do subjetivo e da subjetividade como "irrealidades". 


\section{III}

Husserl situa por volta de 1908 o momento em que ele superou radicalmente o psicologismo sob sua forma a "mais universal", chegando, enfim, a uma diferença nítida entre "a fenomenologia transcendental e a psicologia racional” (HUSSERL, 1975, p. 405). Data deste mesmo período a introdução, na filosofia, do conceito de "fenômeno" no sentido ôntico da palavra, um fenômeno que nunca poderia ser visto como parte real (reell) dos vividos. É claro que não se trata de analisar aqui essa noção tão dificil e debatida de noema, mas apenas de tentar circunscrever a qual exigência teórica ela vinha preencher, que dificuldade ela deveria resolver. Se a redução revela, como sublinha Husserl, "uma camada de subjetivo original", é porque ela revela "a camada do subjetivo ôntico" (HUSSERL, 1973b, p. 405). Se existe aqui um "subjetivo original", é porque através desse conceito o que se persegue, na verdade, é a dificultosa elaboração de uma noção de fenômeno subjetivo que, todavia, não tenha mais nada a ver com o "psíquico" da psicologia tradicional. E exatamente por isso a noção de noema era essencial ao projeto filosófico do autor, ao dar direito de cidadania a um "fenômeno subjetivo" que, por princípio, não se confundia mais nem com o "fenômeno físico", nem com o "fenômeno psíquico" de Brentano, que por tanto tempo desviaram a filosofia do bom caminho, condenando-a a sempre perambular no terreno das "realidades". E já era com esse perfil que a noção estreava em 1907. Enquanto ciência absolutamente "não objetivante", assegura Husserl, para a fenomenologia existe "apenas um ser, o ser dos fenômenos, e este ser não é nenhum ser real” (HUSSERL, 1984, p. 409). Ela não trata nem da realidade fisica nem da realidade psíquica, mas apenas de "fenômenos" - e os fenômenos no sentido ôntico são significações, uma esfera, garante Husserl, "que reside antes daquela do ser no sentido dos reais" (HUSSERL, 1984, p. 411). O fenômeno é o meio ideal pelo qual temos acesso à realidade. O noema, dirá Husserl, não é senão "a generalização da idéia de significação para o domínio completo dos atos" (HUSSERL, 1971, p. 89). Desde então, se as significações da linguagem são idealidades que nunca podem ser vistas como partes reais dos atos, essa mesma idealidade pertence às significações nos noemas, enquanto estes são habitados por tais componentes ideais (HUSSERL, 1987b, p. 
217)7. Para escapar das armadilhas do "psicologismo", é ao modelo da linguagem que se vai recorrer, como se a fenomenologia, última das grandes "filosofias da consciência" de nosso tempo, antecipasse o seu obituário para abrir caminho ao "paradigma da linguagem".

O vínculo entre o fenômeno no sentido "ôntico" da palavra e o motivo antipsicologista já se atestava nos cursos de 1906-07. Se a fenomenologia não se reportava ali a uma subjetividade individual, mas a uma subjetividade em geral, compreende-se que seu território não se confunda com aquele da psicologia empírica. Mas por que ele não seria o mesmo domínio já explorado pela psicologia racional? Essencialmente, dirá Husserl, porque os atos subjetivos fluentes e temporalmente determinados têm um conteúdo de significação ideal que nunca pode ser visto como parte real (reell) dos atos (HUSSERL, 1984, p. 169). Por isso, quando Husserl se pergunta ali pelo significado da fenomenologia para a psicologia, é para reconhecer que ela tem relevância imediata para a "ciência positiva" apenas enquanto noética ou "fenomenologia dos vividos", não enquanto "fenomenologia da constituição da objetidade" (HUSSERL, 1984, p. 240-241). E quando textos posteriores forem atribuir ao noema algum interesse para a psicologia, tratar-se-á agora de uma psicologia tão reformada face à tradicional, que não é surpreendente que, ali no final da Crise das ciências européias, ela termine por perder sua autonomia para ser pura e simplesmente absorvida pela fenomenologia transcendental (HUSSERL, 1962, p. 261).

É precisamente por ser a complexa elaboração de uma noção não psíquica de fenômeno subjetivo que Husserl se preocupará, insistentemente, em sublinhar que o noema não tem nada a ver com a "realidade". Através do seu sentido, o fenômeno ôntico se retira da esfera da realidade. Assim, se é certo que o noético e o noemático estão essencialmente correlacionados entre si, não é menos certo, dirá Husserl, que eles apontam para duas "regiões de ser" que são "radicalmente opostas", e que o noemático é uma "objetidade singular". Uma objetidade bastante singular, visto que enquanto "os objetos puros e simples (entendidos em sentido não modificado) estão sob gêneros supremos fundamentalmente distintos, todos os sentidos de objeto e todos os noemas tomados completamente são por princípio de um único gênero supremo" (HUSSERL, 1950, p. 314). Por isso, sempre se deve frisar a diferença entre 
noese e noema, tão contrária, dirá Husserl, aos "hábitos de pensamento psicologistas" (HUSSERL, 1950, p. 263). Afinal, se poderia haver "bom fundamento" para se caracterizar o lado noético dos vividos como sendo "psíquico" (HUSSERL, 1950, p. 210), o seu lado noemático não se refere mais a qualquer "realidade" que se escandiria em diferentes gêneros, como o "físico" e o "psíquico". Por isso Husserl sublinhará o "abismo" existente entre o objeto "puro e simples", a coisa da natureza, e o "sentido" da percepção desse objeto. Se a árvore "pura e simples" pode queimar ou dissolver-se em seus elementos químicos, o "sentido" da percepção dessa árvore "não pode queimar, ele não tem nenhum elemento químico, nenhuma força, nenhuma propriedade real" (HUSSERL, 1950, p. 222). Afinal, o "percebido enquanto tal" não é a coisa "pura e simples", tal como esta surge para a consciência situada na atitude natural, sempre cega para os modos subjetivos de doação dos objetos. O "percebido enquanto tal", oriundo da redução fenomenológica, é a unidade sintética de seus modos de doação, ele é uma "unidade fenomenal de elementos subjetivos" (HUSSERL, 1968a, p. 176). O noema não designa a realidade mas o fenômeno, quer dizer, o modo como o real torna-se consciente (HUSSERL, 1950, p. 245). Por isso Husserl dirá que, em regime de redução, a exclusão do mundo, "do todo das efetividades reais, significa a inclusão do todo das irrealidades, ao qual co-pertencem todos os correlatos intencionais" (HUSSERL, 1987b, p. 219). Este fenômeno não é nada de psíquico, visto que aquilo que é próprio aos vividos reduzidos "é separado - diz ele - de toda natureza e de toda física, e não menos de toda psicologia, através de um abismo", e que "mesmo essa imagem, enquanto naturalista, não é suficientemente forte para indicar a diferença" (HUSSERL, 1950, p. 222).

Mas qual o sentido de dirigir-se à linguagem para elaborar a noção de "fenômeno subjetivo", e o que garante ao empreendimento a certeza de que ele livra este "fenômeno" de toda e qualquer contaminação pelo "psíquico"? O projeto não teria cabimento no âmbito da doutrina da significação elaborada nas Investigações lógicas. Afinal, se ali Husserl já combatia a identificação "psicologista" das significações da linguagem a imagens ou representações de uma consciência (HUSSERL, 1968b, p. 61-63), resta que em 1901 ele ainda identificava a "idealidade" das significações àquela da "espécie" ou essência do ato de significar (HUSSERL, 
1968b, p. 100). O que inevitavelmente transformava a significação na essência de um fato psíquico. Mas será diferente quando Husserl reconhecer que a significação não se reporta a atos, a nada de específico nos atos, mas é algo de objetivo, o correlato do ato de significar (HUSSERL, 1987a, p. 35), o que isolará a significação “ôntica” do domínio psíquico. Recorrer à linguagem para compreender o que é um fenômeno subjetivo só é estranho para quem identifica, apressadamente, o subjetivo ao interior, ao psíquico, quer dizer, para quem permanece preso à atitude natural, com sua oposição entre "mundo" e "representação". O fenômeno subjetivo não é o interior, mas sim o modo de doação parcial e variável dos objetos, e por isso mesmo o subjetivo assim compreendido é anterior à partilha usual entre consciência e linguagem, e reina soberano nessas duas esferas que se supõe opostas. Afinal, não estamos em situações essencialmente diferentes quando reconhecemos que um objeto só pode ser dado à percepção segundo perspectivas parciais e variáveis, ou quando verificamos que, através da linguagem, só podemos nos referir a determinada pessoa como sendo ou o vencedor de Iena ou o vencido de Waterloo, ou através de qualquer outra significação, que sempre nos apresentará o objeto em um como parcial e variável (HUSSERL, 1987a, p. 41). Donde a certeza de Husserl, expressa na Krisis, de que toda a tradição da filosofia moderna foi cega para o verdadeiro significado do "subjetivo", precisamente por contentar-se em localizá-lo na interioridade do sujeito psicológico, calando-se sobre idéia de "modo subjetivo de doação" ainda, no plano da análise fenomenológica estática, o mesmo princípio que torna necessária a fenomenalização da experiência para a consciência, faz com que seja inevitável a multiplicação indefinida das significações com as quais nós nos reportamos ao mundo através da linguagem. Como não existe objeto absolutamente simples a ser expresso pela linguagem ou dado a uma intuição, visto que todo objeto estabelece relações com os demais, relações que são constitutivas de cada objeto, é inevitável a multiplicação indefinida ou mesmo infinita de seus modos de doação ${ }^{9}$. Por isso Husserl caracterizará a significação como um objeto categorial, aquilo que exprime algo em um como determinado e variável, segundo tal ou tal relação (HUSSERL, 1987a, p. 45). É a significação assim compreendida que será generalizada para o domínio completo dos atos, atribuindo um componente "lógico" ao domínio dos fenômenos subjetivos. 
Mas será que essa tentativa de afastar o fenômeno subjetivo do "psíquico", assimilando-o às significações da linguagem, não encontraria um limite bem preciso e bastante decisivo? Vá lá que tanto as significações quanto o fenômeno no sentido "ôntico" da palavra não sejam nada de "interior" a uma consciência, no uso natural e psicológico do termo. Mas resta que Husserl sempre protestou contra a assimilação "psicologista" das significações da linguagem a "representações" privadas de uma consciência, precisamente para preservar o seu caráter essencialmente público. Os fenômenos subjetivos, sendo a apresentação variável do objeto a uma consciência, não seriam inevitavelmente um assunto privado? Por um lado, não faltam textos que possam levantar essa suspeita. Afinal, quando Husserl descrevia o "modo de ser" do noema ali no primeiro livro de Idéias, era para apresentá-lo como um objeto completamente "dependente", cujo esse consiste exclusivamente em seu percipi (HUSSERL, 1950, p. 246). Mais ainda, em um texto de 1912 ele afirma que, se o mundo circundante é o mesmo para distintos egos, as multiplicidades de fenômenos em que se constitui uma coisa real são diferentes para cada um deles (HUSSERL, 1971, p. 109-110). O que significa pura e simplesmente decretar que os fenômenos são estritamente privados, nunca intersubjetivos.

Mas, sob esse ponto preciso, Husserl fará a sua autocrítica em diversos textos dos anos 1915 a 1921, textos em que ele atribui aos fenômenos "uma espécie de objetividade" (eine Art Objektivität) (HUSSERL, 1973b, p. 285). Se, do ponto de vista da "objetividade da natureza", os fenômenos são sempre "fenômenos puramente subjetivos", Husserl insistirá agora na necessidade de se reconhecer, todavia, que cada um dos fenômenos tem sua existência (Dasein) e o seu "ser em si", enquanto membros de um sistema que congrega a totalidade dos fenômenos possíveis, que são apenas "atualizados" nesta percepção singular que é a minha ou a de outrem. Assim, se é evidente que a experiência de outrem não é a minha, todavia ele tem acesso aos mesmos fenômenos que pertencem ao meu sistema de fenômenos, assim como eu terei acesso aos seus fenômenos, quando ocupar o seu mesmo lugar, quando eu me situar no interior do mesmo sistema de relações em que atualmente ele se instala (HUSSERL,1987b, p. 87) ${ }^{10}$. Afinal, se o objeto é uma idéia situada no infinito, ele pode atualizar-se em uma percepção que é apenas uma das 
atualizações possíveis dessa idéia. E é só assim - dirá Husserl - que se compreende como aquilo que é atualizado por um sujeito pode ser atualizado por um outro como sendo o mesmo. Esses sujeitos reportam-se não apenas à mesma natureza, garante Husserl, mas também ao mesmo sistema de "fenômenos perspectivos" (HUSSERL, 1973b, p. 287). Assim, se toda percepção está individuada por seu lugar na temporalidade imanente, na verdade ela torna efetivo (verwirklicht) algo que existe "em si”. Se cada percepção tem seu "sentido" individual, este sentido é algo de ideal e por isso mesmo duas percepções que coincidem têm idêntico sentido e idêntico objeto, apesar de sua separação real (reelt). Por isso, ninguém deve dizer que a série de fenômenos que eu atribuo a outrem seja uma segunda série face à minha. Ela é a mesma série, que eventualmente eu poderia ter, a percepção de outrem torna efetivos os mesmos modos de manifestação (Erscheinungsweisen) de objetos que estão aí para mim, mas que atualmente eu não torno efetivos (HUSSERL, 1973b, p. 288). Logo, se todo fenômeno é membro de um circuito aberto e sem fim de fenômenos, apenas não explicitamente efetivados, então - dirá Husserl - é preciso reconhecer que "a subjetividade desses fenômenos é a intersubjetividade aberta" (HUSSERL, 1973b, p. 289). Donde a correção essencial que, em 1917, Husserl fará à doutrina exposta no primeiro livro de Idéias: no caso dos objetos transcendentes, não se deve mais afirmar que seu esse se reduz ao seu percipi (HUSSERL, 2001, p. 192) E se é assim, o fenômeno subjetivo que se quer circunscrever com o noema só poderá ser mesmo uma irrealidade, algo que pode se efetivar em diferentes subjetividades, e que por princípio não é nada de psíquico. Efetivamente, a exposição do mundo não está, ela mesma, no mundo, essa exposição não pertence ao domínio da "realidade". ${ }^{11}$

Quando Husserl contrasta o "modo de ser" das realidades àquele das irrealidades, ele o faz em termos estritamente temporais. Uma realidade, como uma coisa natural, tem sua duração no tempo objetivo e é individuada por seu lugar nesse tempo. Um objeto imanente, como uma sensação ou um ato, se desdobra na temporalidade imanente à consciência, onde ele tem sua duração e uma individuação temporal. Os irreais, ao contrário, não têm como forma de sua existência nem o tempo objetivo nem o tempo imanente, eles não estão em qualquer tempo. Assim, um irreal não tem situação temporal, não tem duração temporal, ele não é 


\section{2}

individuado em um ponto do tempo, ele está em todas as partes e em parte alguma (HUSSERL, 1954, p. 313). E se o irreal pode se apresentar em atos individuais que estão em algum lugar temporal, essa ligação secundária com o tempo não o torna temporal. Ele só se encontra no tempo de maneira contingente, a duração não pertence à sua essência, ele permanece o mesmo que pode se encontrar em não importa qual tempo (HUSSERL, 1954, p. 314). E Husserl não deixará de frisar que o "experimentado enquanto noema não é momento do ato, passando com este, mas o idêntico de atos renovados e livremente renováveis...", ele é "um supratemporal" e apenas referido a uma "temporalidade"12. Assim, há um logos fenomenal à disposição dos sujeitos dessa comunidade fenomenológica, pronto para ser atualizado a cada percepção singular, assim como as significações supratemporais da linguagem estão disponíveis para nós, para serem "atualizadas" a cada ato concreto de fala. E por isso a fenomenologia, disciplina cuja biografia já foi tão associada ao "subjetivismo", na verdade orientou-se progressivamente em direção a uma filosofia do espírito "objetivo"13.

\section{IV}

Qual será o rosto do "transcendental" husserliano, quando se procura desenhar sua silhueta a partir da oposição entre "realidade" e "irrealidade"? Se o fenômeno no sentido "ôntico" da palavra pode ser apresentado como um "irreal”, assim como as significações da linguagem, resta que ele é o correlato de um jogo entre sensações e noeses que, estas, se desdobram na temporalidade imanente à consciência, têm ali o seu lugar temporal e a sua individuação. Logo, não é neste plano que se torna "pensável” uma consciência sem alma, um fluxo em que os vividos, no sentido psicológico da palavra, não têm apoio nem validade. E não era uma ambigüidade menor do primeiro livro de Idéias prometer delinear ali a região do "absoluto transcendental", mesmo confessando deixar fora de consideração o absoluto "último" e "verdadeiro", situado na consciência constituinte do tempo (HUSSERL, 1950, p. 198). Mas Husserl faz um uso funcional de muitos de seus conceitos, o que lhe permitirá discernir, por exemplo, vários estratos do "subjetivo" (HUSSERL, 1962, pp. 182- 
183). Ele também distinguirá entre duas camadas do transcendental, uma "superficial" e outra "profunda". Se a primeira está situada na temporalidade imanente, a camada "profunda" não está nem no tempo objetivo, nem no tempo fenomenológico (HUSSERL, 2001, p. 184). E sabe-se que Husserl apresentará a consciência absoluta constituinte do tempo como sendo, ela mesma, "sem tempo" (HUSSERL, 1966, p. 112). Donde a sua insistência em sublinhar que ninguém pode aplicar aos fenômenos constituintes últimos os predicados temporais do constituído. Não tem cabimento afirmar desses fenômenos da subjetividade absoluta que eles estariam no "agora", que eles teriam sido "antes" ou serão "depois", não podemos dizer que eles se sucedem temporalmente ou são simultâneos entre si (HUSSERL, 1966, p. 75). Assim, a consciência do "agora" não está, ela mesma, no agora; a retenção que está junto à consciência do agora não é "simultânea" ao agora, visto que "simultaneidade" é predicado de objeto já constituído, de objeto individual no tempo. Por isso, se posso dizer que uma recordação é "simultânea" a alguma outra coisa, é porque ela já é um ato da consciência, um objeto imanente que se desdobra no tempo fenomenológico. Mas a retenção não é a recordação, ela não é nada de situado no tempo imanente, ela é um evento da consciência constituinte do tempo e, enquanto tal, ela é intemporal (HUSSERL, 1966, p. 334). É aqui que estará o domínio dos vividos absolutos que, por serem pré-temporais, não têm mais qualquer semelhança, nem mesmo remota, com o "anímico" ou "psíquico". Por esse viés, novamente, a subjetividade transcendental não pode mais ser vista como "parte" do mundo, físico ou psíquico, afastando-se radicalmente da esfera das "realidades". Esse resultado é uma conseqüência inevitável da lógica que comanda a doutrina husserliana, que em todos os níveis da "constituição" sempre parte da identidade dos objetos para regredir às multiplicidades constitutivas. O fluxo da consciência constituinte do tempo é a multiplicidade última à qual se chega no percurso regressivo. Ela é uma pura multiplicidade, um puro fluir onde não existe mais nenhuma identidade. E se é assim, os eventos dessa consciência absoluta são o "subjetivo" no sentido o mais alto da palavra, eles são os fenômenos no sentido absoluto, os vividos antes de toda e qualquer objetivação, aquilo que é anterior à esfera dos objetos imanentes situados no tempo fenomenológico. Assim, não é surpreendente que a análise fenomenológica genética loca- 


\section{4}

lize a fenomenalização originária da experiência neste domínio do absoluto, no momento em que um "agora" é empurrado para o passado por um novo presente, mas também "retido" na impressão do novo "agora", que conserva consigo o "perfil" (Abschattung) do momento que se escoou (HUSSERL, 1966, p. 81). Sendo assim, é entre a retenção e o objeto temporal imanente que se instalam a cisão e a união originárias entre o fenômeno e o objeto, entre o subjetivo e o objetivo, entre o transcendental e o mundano, entre o intemporal e o temporal, entre o irreal e o real, a cisão e a união originárias entre aquilo que reciprocamente se exclui e, por outro lado, essencialmente se exige ${ }^{14}$.

Mas Husserl não hesitou quanto a essa caracterização da consciência "absoluta" como um fluxo "não temporal" de vividos? É certo que, ao lado da série de textos que decretam a intemporalidade da subjetividade última, existe toda uma outra série, em que se descreve esse fluxo como sendo uma ordenação unidimensional "quase-temporal", ou que tem como sua "forma" uma temporalidade "pré-fenomenal" ou "pré-imanente” (HUSSERL, 1966, p. 380-381). Assim como Husserl também afirmará que o transcendental da "primeira camada", o tempo fenomenal, é possível apenas graças a um "tempo transcendental”, situado no transcendental da "segunda camada"15. Mas resta que essa indecisão doutrinal relativa à "forma" do ser absoluto não altera em nada aquela que é, no fundo, a tese husserliana fundamental: quer essa subjetividade última seja caracterizada como intemporal, quer ela tenha como sua forma uma outra temporalidade, em qualquer um dos casos será preciso reconhecer que na região do "absoluto" não pode haver lugar para qualquer duração - e este é o ponto principal.Afinal, “duração” é a forma de algo que dura, de um ser duradouro, de uma identidade na série temporal que opera como sua duração (HUSSERL, 1966, p. 113). Mas a subjetividade absoluta é o domínio das últimas multiplicidades, em que não há mais qualquer identidade, apenas um perpétuo fluir. Neste domínio dos vividos anteriores a toda objetivação há um puro vir-a-ser (Werden), uma mudança contínua, enquanto a duração supõe algo de permanente, algo que perdure sob a mudança. Ali onde a consciência não opera sínteses e não põe na duração a identidade de algo que dura, não existe nenhuma duração, apenas um vir-a-ser, um perpétuo fluir (HUSSERL, 1966, p. 296). Desde então, se os fenômenos constituintes do tempo são outro 
tipo de "objetidades" que aquelas constituídas no tempo, é essencialmente porque eles não são realidades, não são individuados por qualquer lugar temporal, eles não são objetos individuais nem processos individuais (HUSSERL, 1966, p. 75).

O ego pré-monádico ao qual a fenomenologia chega através da "última redução", enquanto ele é o polo idêntico para todas as séries temporais, só poderá ser "supra" temporal (HUSSERL, 2001, p. 277). Donde o contraste sistemático que Husserl fará entre a mônada e o ego originário. Se toda mônada tem nascimento e desenvolvimento, uma história, se ela é uma unidade constituída em um tempo monádico de um mundo monádico, o ego absoluto é intemporal, ele é o suporte (Träger) de toda temporalização. Desde então, se em relação ao sujeito humano a mônada é o transcendental, será preciso reconhecer que o ego absoluto é transcendental em um "segundo sentido" (HUSSERL, 1973c p. 439 e p. 587). Por isso Husserl não deixará de sublinhar que, enquanto nós falamos em "presente" e "passado", enquanto permanecemos no plano das modalidades temporais, ainda não chegamos ao domínio do "transcendental último" (HUSSERL, 1973c, p. 584). O ego absoluto não começa e passa como um vivido, ele não pode nascer ou perecer como o homem natural, ele é um eu "permanente e constante" (stehendes und bleibendes), sem qualquer extensão temporal, um eu “eterno" (HUSSERL, 2001, p. 286; 1973b, p. 157). Por isso, quando Husserl afirma que este ego tem uma vida "originariamente presente", ele não deixa de relembrar que este "presente originário" (Urgegenwart) não é nenhuma "modalidade temporal" (HUSSERL, 1973c, p. 668), mas antes um presente eterno de onde se assiste à constituição do presente, do passado e do futuro enquanto modalidades temporais. Assim, se todos os entes são ligados a um lugar temporal que os individua, então - dirá Husserl - o ego absoluto não é um ente (Seiende), mas a contrapartida de todo ente, ele não é objeto, mas o lugar originário (Urstand) de toda objetidade e, se este ego é um indivíduo, ele não é nada de real, mas um indivíduo "omnitemporal" (HUSSERL, 2001, p. 277 e p. 286). Sendo assim, se o ego monádico pode relacionar-se a outros egos, é erroneamente que chamamos o ego absoluto de "eu", visto que diante dele um "alter ego" não tem sequer sentido (HUSSERL, 1973c, p. 586). Propriamente falando, dirá Husserl, esse eu nem deveria chamar-se "eu”, aliás, ele não deveria chamar-se nada, 
visto que qualquer nominação o torna objeto, quando ele é necessariamente sujeito absoluto, aquilo que nunca pode ser diretamente objeto, e por isso mesmo permanecerá sempre anônimo. Ele é o sem nome (Namenlose) acima de todo apreensível, acima de todo não permanente (HUSSERL, 2001, p. 278). Desde então, nenhuma surpresa se Husserl for caracterizar este ego último como um "ideal idêntico". O ego operante (fungierende), enquanto presente permanente, só poderá ter o "modo de ser" daquilo que está em todas as partes e em parte alguma, o "modo de ser" de um "irreal” (HUSSERL, 2001, p. 280; cf. HELD, 1966, 124). E se através da monadização o ego absoluto se auto-explicita em uma multiplicidade monádica (HUSSERL, 1973c, p. 589), se por meio de seus atos este ego adquire uma localização temporal, isso não o torna efetivamente temporal (HUSSERL, 2001, p. 280), assim como as significações da linguagem se relacionam com o tempo ao se encarnarem nos signos físicos, sem por isso se tornarem, elas mesmas, temporais. Este ego absoluto será o sujeito último não apenas de todos os vividos, mas também daquilo que está “onticamente incluído nos vividos" (HUSSERL, 2001, p. 277), quer dizer, este ego será o sujeito último não só de todas as séries temporais como também daquele logos fenomenal que possui uma "espécie de objetividade" e que é "atualizado" a cada percepção singular.

Se é assim, qual será o "modo de ser" da subjetividade transcendental, quando a avaliamos a partir da oposição husserliana entre realidade e irrealidade? O resultado a que se chegou é, na verdade, um híbrido. Como "irrealidades", temos apenas a primeira e a última multiplicidade, a multiplicidade noemática e supratemporal de que se partiu e a multiplicidade pré-temporal da consciência constituinte do tempo, a subjetividade absoluta com seu ego puro e "eterno". É aqui que estamos em domínios que não se confundem com a alma ou a psique. Mas resta que aquelas multiplicidades são mediadas pela região da consciência no sentido noético, domínio de sensações e atos que se desdobram na temporalidade imanente, têm ali o seu lugar temporal e sua individuação e são, por isso mesmo, "realidades". Pelo uso funcional que Husserl faz de seus conceitos, essa esfera noética é aquela do transcendental da "primeira camada" ou "superficial". Mas esse mesmo uso funcional permite dizer que este transcendental da "primeira camada" é, na verdade, a primeira "mundanização", a primeira objetivação da "psique", mesmo que esta 
psique ainda não seja ligada a um corpo, ainda não se tenha tornado "empírica". Afinal, para o próprio Husserl aquilo que experimenta a “objetivação empírico-psicológica não é a consciência absoluta, mas sim percepções, recordações, expectativas” (HUSSERL, 1984, p. 421), quer dizer, o estrato noético da consciência. E não faltam textos em que ele reconhecerá que os fenômenos noéticos, individuados na temporalidade imanente, são processos "psíquicos” (HUSSERL, 1929, p. 148; 1950, p. 210). E se é assim, a questão da identidade e da diferença entre o transcendental e o psicológico na verdade se interioriza na própria subjetividade transcendental, e se apresenta bem antes do problema clássico de se saber como essa subjetividade, que está "fora" do mundo, se "apercebe" como "parte" do mundo.

O que destinava a fenomenologia, mesmo partindo da exigência teórica de uma subjetividade transcendental que só poderia ser uma "irrealidade", a assentar-se, na prática, naquele transcendental híbrido ao qual Husserl chegava, misto de realidade e de irrealidade, de psíquico e de não psíquico? Salvo melhor juízo, aparentemente existem razões históricas na origem desse desfecho. Este resultado parece ser a conseqüência final dos impasses a que é levado um projeto fundacionista, seja da aritmética e da lógica, seja da possibilidade do conhecimento em geral, que começa a desdobrar-se no interior de uma filosofia da consciência cuja certidão de nascimento é empirista, com registro na Psicologia do ponto de vista empírico de Brentano. Nas suas Lições de 1906-07 Husserl frisava que, para se chegar à fenomenologia e à teoria do conhecimento, o "ponto de partida metódico conforme à natureza" é a "psicologia", a "consciência natural" (HUSSERL, 1984, p. 212). Mas como compatibilizar um projeto fundacionista radical com esse modelo de consciência? A fenomenologia procura solucionar as evidentes dificuldades do empreendimento através de sucessivas "purificações" de seu "ponto de partida", mas sem abandoná-lo jamais. Redução "eidética” para se superar o psicologismo lógico, redução "transcendental" para se superar o psicologismo sob sua forma "a mais essencial", mas sem nunca renunciar, efetivamente, ao domínio dos "fenômenos psíquicos" dos quais se partira. São eles que permanecem na cena filosófica husserliana como a região da noética, a camada de realidade interposta entre as irrealidades. Era o seu ponto de partida que condenava a fenomenologia a trabalhar com uma subjetivi- 
dade que, na verdade, segundo os seus próprios critérios, só poderia ser um "duplo" mundano-transcendental, e por isso mesmo já era o seu ponto de partida que a destinava a desdobrar-se em uma "explicação" infindável sobre a identidade e a diferença entre o "psicológico" e o "transcendental".

${ }^{1}$ Carta de Heidegger a Husserl, de 22 de outubro de 1927(in HUSSERL, 1968a, p. 602).

2 Cf Husserl, 1973a, p. 117: "Querer apreender o universo do ser verdadeiro como algo que está fora do universo da consciência possível, do conhecimento possível, da evidência possível, ambos relacionados um ao outro de maneira puramente exterior, através de uma lei fixa, é absurdo. Essencialmente ambos se co-pertencem, e essencialmente aquilo que se co-pertence também é concretamente um, um na única concreção absoluta da subjetividade transcendental. Se ela é o universo do sentido possível, então um exterior a ela é um não senso".

3 Uma "solução" já sugerida por Ingarden, mesmo reconhecendo que Husserl a consideraria inaceitável. Cf. INGARDEN, R., observações críticas às Meditações Cartesianas, in HUSSERL, 1973a,. 214.

${ }^{4}$ Cf. BRENTANO, 1944, p. 92: "O mundo inteiro de nossos fenômenos se divide em duas grandes classes, a classe dos fenômenos físicos e aquela dos fenômenos psíquicos".

5 HUSSERL, Manuscrito A I 36, p. 193 a (1920), apud KERN, 1964, 235.

${ }^{6}$ Cf. Ibid, p. 325: "O reino da natureza é o reino do 'fenomenal', isso significa aqui: das unidades reais (realen) que se constituem na ou por meio da exposição; o reino do espírito é o reino das realidades (Realitäten)... dadas através de manifestação absoluta, aquelas que têm atrás de si apenas o eu puro como irreal (irrealen), suporte absoluto de toda manifestação de realidade (Realität)".

7 Esse "sentido" será essencial ao noema, e por isso Husserl dirá que se o noema completo envolve não só o sentido, mas também outros caracteres e a sua plenitude intuitiva, resta que esse sentido é a "camada nuclear" em que se fundam todos os demais momentos. Cf HUSSERL, 1950, p. 223.

8 Cf HUSSERL, 1962, p. 168: "Nunca (quer dizer, nunca antes da primeira abertura da 'fenomenologia transcendental' nas 'Investigações lógicas') a correlação do mundo (do mundo do qual nós sempre falamos) e dos seus modos subjetivos de doação tinha provocado o espanto filosófico, se bem que ele já se tivesse feito sentir na filosofia pré-socrática e na sofística, mas somente como motivo de uma argumentação cética. Jamais essa correlação despertou um interesse filosófico próprio, que tivesse feito dela o tema de uma cientificidade própria”.

9 Cf. HUSSERL, 1968b, p. 50: "Assim, diferentes significações podem pertencer à mesma intuição (mas categorialmente apreendida de modo diferente) e com isso ao mesmo objeto".

doispontos, Curitiba, São Carlos, vol. 3, n. 1, p.37-61, abril, 2006 
10 Cf. HUSSERL, 1987b, p. 87: “Os fenômenos, enquanto fenômenos da consciência correspondente... são certamente algo e têm sua existência (Existenz)"

11 Seguindo uma interpretação inaugurada por Fink, De Boer vê nessa série de oposições entre o noema e a "realidade", estabelecidas por Husserl desde o primeiro livro de Idéias, uma nítida recaída no psicologismo (cf . DE BOER, 1978, pp. 425 a 429). O verdadeiro noema transcendental precisaria ser idêntico ao real e, ao fazer essa série de distinções, Husserl escorregaria para uma versão psicológica do noema, que seria agora algo de psíquico que "representaria" o real na consciência. Os textos de Husserl não dão qualquer caução a essa interpretação. Eles afastam enfaticamente o noema da região do "psíquico" e lhe atribuem "algo de lógico". O noema não designa a realidade, mas o fenômeno, o modo como o real torna-se consciente. E a exposição (Darstellung) do objeto no fenômeno não é de forma alguma uma "representação", severamente criticada por Husserl nessas páginas.

12 HUSSERL, Manuscrito A VI 30, pp. 39 a/b e 40 a (entre 1918 e 1921), apud MARBACH, 1974,318 .

13 Rudolf Bernet, em seu artigo sobre "O conceito de noema” (in BERNET, 1994. pp. 65 a 92), declara guerra aberta aos textos de Husserl ao afirmar, sem declinar qualquer razão, que "há pouco sentido" em se determinar o noema como "algo de idêntico e de supra temporal"'(pp. 71/2). Afirmando dogmaticamente essa tese, o autor considera então "como adquirido" que o correlato noemático de um ato "é individualizado temporalmente, exatamente como o próprio ato" (p. 72). Bernet sublinha a "não independência" do noema, afirmada no primeiro livro de Idéias, mas omite ou corrige todos os textos em que Husserl apresenta o noema como a generalização da idéia de significação para o domínio completo dos atos, e lhe atribui um componente "lógico". Assim como omite os textos em que Husserl desfaz a equivalência entre esse e percipi no domínio dos transcendentes, bem como aqueles que conferem ao fenômeno no sentido ôntico uma espécie de "objetividade". O resultado desta hermenêutica em que sistematicamente se omite ou se corrige os textos não se faz esperar: o noema é contrabandeado para a região do psíquico, visto que o autor o situará na "esfera do mental” (p. 75). Pior ainda, a fenomenologia assim emendada reata com a doutrina clássica da representação, expressamente criticada por Husserl: o noema será apresentado por Bernet como "representante mental da coisa real" (p. 75).

14 Cf. HUSSERL, 1984, p. 430: "Finalmente chegamos à consciência do tempo como à última. Entre ela e o objeto posto e legitimamente posto no conhecimento há uma série de objetos 'ideais', nós poderíamos dizer de significações no sentido amplo e de fenômenos”.

15 Cf. HUSSERL, 2001, 29. Além da indecisão quanto às teses filosóficas, característica desses "manuscritos de pesquisa", Husserl também vacila ali quanto à terminologia. Assim, à p. 184 a expressão "tempo transcendental” será empregada para designar o "tempo fenomenológico", ou o transcendental da "primeira camada".

doispontos, Curitiba, São Carlos, vol. 3, n. 1, p.37-61, abril, 2006 


\section{Referências bibliográficas}

BERNET, R. 1994. La vie du sujet. Paris: PUF.

DE BOER, Th. 1978. The Development of Husserl's Thought. Haag:

Martinus Nijhoff.

HUSSERL, E. 1950. Ideen zu einer reinen Phänomenologie und phänomenologischer Philosophie. Erstes Buch. Husserliana, Vol. III. Haag: Martinus Nijhoff.

HUSSERL, E. 1952. Ideen zu einer reinen Phänomenologie und phänomenologischer Philosophie. Zweites Buch. Husserliana, Vol. IV. Haag: Martinus Nijhoff.

HUSSERL, E. 1954. Erfahrung und Urteil. Hamburg: Glassen \& Goverts. HUSSERL, E. 1959. Erste Philosophie. Husserliana,Vol.VIII. Zweiter Teil. Haag: Martinus Nijhoff.

HUSSERL, E. 1962. Die Krisis der europäischen Wissenschaften und die transzendentale Phänomenologie. Husserliana,Vol.VI. Haag: Martinus Nijhoff.

HUSSERL, E. 1966. Zur Phänomenologie des inneren Zeitbewusstsein. Husserliana, Vol. X. Haag: Martinus Nijhoff.

HUSSERL, E. 1968a. Phänomenologische Psychologie. Husserliana, Vol. IX. Haag: Martinus Nijhoff.

HUSSERL, E. 1968b. Logische Untersuchungen.Vol. II/1. Tübingen: Max Niemeyer.

HUSSERL, E. 1971. Ideen zu einer reinen Phänomenologie und phänomenologischen Philosophie. Drittes Buch. Husserliana, Vol.V. Haag: Martinus Nijhoff.

HUSSERL, E. 1973a. Cartesianische Meditationen und Pariser Vorträge. Husserliana, Vol. I. Haag: Martinus Nijhoff.

HUSSERL, E. 1973b. Zur Phänomenologie der Intersubjektivität. Zweiter Teil. Husserliana, Vol. XIV. Haag: Martinus Nijhoff. 
HUSSERL, E. 1973c. Zur Phänomenologie der Intersubjektivität. Dritter Teil. Husserliana, Vol. XV. Haag: Martinus Nijhoff..

HUSSERL, E. 1975. Articles sur la logique. Paris: PUF.

HUSSERL, E. 1984. Einleitung in die Logik und Erkenntnistheorie -

Vorlesungen 1906-1907. Husserliana, Vol. XXIV. Haag: Martinus Nijhoff.

HUSSERL, E. 1987a. Vorlesungen über Bedeutungslehre. Husserliana, Vol XXVI. Haag: Martinus Nijhoff.

HUSSERL, E. 1987b. Ausätze und Vorträge (1911-1921). Husserliana, Vol. XXV. Haag: Martinus Nijhoff.

HUSSERL, E. 1989. Aufsätze und Vorträge (1922-1937). Husserliana, Vol. XXVII. Dordrecht: Kluwer Academic Publishers.

HUSSERL, E. 2001. Die Bernauer Manuskripte über das Zeitbewusstsein. Husserliana,Vol. XXXIII. Dordrecht: Kluwer Academic Publishers.

KERN, I. 1964. Kant und Husserl. Haag: Martinus Nijhoff.

MARBACH, E. 1974. Das Problem des Ich in der Phänomenologie Husserls. Haag: Martinus Nijhoff.

MERLEAU-PONTY, M. 2002. Notes inédites de la Bibliothèque National pour Le visible et l'invisible (transcritas por Renaud Barbaras). 